\title{
EVIDÊNCIAS DA PLASTICIDADE E ATUALIDADE \\ DA DIVISÃO SEXUAL DO TRABALHO \\ A PARTIR DE QUATRO MODALIDADES CONCRETAS
}

\section{EVIDENCE OF THE PLASTICITY AND TOPICALITY \\ OF THE SEXUAL DIVISION OF LABOR \\ FROM FOUR CONCRETE MODALITIES}

\author{
Bianca Briguglio* \\ Fabiana Sanches Grecco ${ }^{* *}$ \\ Raquel Oliveira Lindôso ${ }^{* * *}$ \\ Thaís de Souza Lapa ${ }^{* * *}$
}

\section{Resumo}

Neste artigo, partimos de quatro diferentes modalidades concretas de trabalho: na indústria metalúrgica; na indústria de confecções; nas cozinhas de restaurantes; e no trabalho de catação de materiais recicláveis, para evidenciar a divisão sexual do trabalho, conforme as sociólogas do trabalho, feministas materialistas, Helena Hirata e Danièle Kergoat, a compreendem: como expressão da base material das relações de gênero na sociedade capitalista, regida pelos princípios de separação e de hierarquia, que organizam a divisão social do trabalho entre os gêneros e distribui desigualmente os trabalhos produtivos, domésticos e de cuidados. Com isso, reafirmamos essa concepção de divisão sexual do trabalho como uma chave de leitura teórico metodológica atual, com caráter plástico e comparativo.

Palavras-chave: Divisão sexual do trabalho. Catação de materiais recicláveis. Indústrias metalúrgica e de confecções. Cozinhas profissionais.

\begin{abstract}
In this article, we departure from four different concrete work modalities: work in the metallurgical industry, in the clothing industry, in restaurant kitchens, and in the collecting recyclable materials work, to highlight the sexual division of labor, as the sociologists of labor, feminist materialists, Helena Hirata and Danièle Kergoat, understand it: as the material basis expression of gender relations in capitalist society, governed by the principles of separation and hierarchy, which organize the social division of labor between genders and unevenly distribute productive, domestic and care work. With that, we reaffirm this conception of sexual division of labor as a current methodological reading key, as a plastic and comparative feature.

Keywords: Sexual division of labor. Collection of recyclable materials. Metallurgical and confection industries. Professional kitchens.

\footnotetext{
* Doutora em Ciências Sociais pela Universidade Estadual de Campinas (IFCH-Unicamp). E-mail: biancabrig@ gmail.com

** Doutora em Ciência Política (IFCH-Unicamp). E-mail: fasgrecco@gmail.com

*** Doutoranda em Ciências Sociais (IFCH-Unicamp). E-mail: raquel.lindoso@yahoo.com.br

**** Doutora em Ciências Sociais (IFCH-Unicamp). Professora do Departamento de Sociologia e Ciência Política da Universidade Federal de Santa Catarina (UFSC). E-mail: thais_lapa@yahoo.com.br
} 


\section{Introdução}

Esses princípios [separação e hierarquia] são válidos para todas as sociedades conhecidas, no tempo e no espaço. Isso não significa, no entanto, que a divisão sexual do trabalho seja um dado imutável. Ao contrário, ela tem uma incrível plasticidade: suas modalidades concretas variam bastante no tempo e no espaço (HIRATA; KERGOAT, 2008, p. 266-267).

A formulação de um instrumento analítico para examinar as relações de trabalho de modo sexuado na "teoria geral" do trabalho é uma das contribuições centrais da produção teórica de Danièle Kergoat e Helena Hirata. A reafirmação dessas autoras a respeito da centralidade do trabalho traz uma contribuição de perspectiva materialista à produção da teoria feminista. A compreensão de “divisão sexual do trabalho", evidenciada como uma categoria metodológica por ambas, é certamente a elaboração teórica das autoras que mais se espraiou e foi utilizada em diversas pesquisas, seja meramente descrevendo a separação e a hierarquia em distintos processos de trabalho ou, de maneira ampliada, compreendendo a divisão sexual do trabalho social como um todo.

A compreensão de Kergoat e Hirata envolve, de um lado, a implosão da noção de que o trabalho assalariado se restringe à atividade produtiva do trabalhador masculino, qualificado, branco. De outro lado, incorporou a reivindicação do caráter de trabalho das atividades realizadas no âmbito doméstico. Pretendeu-se radicalizar a análise do trabalho ao produzir novos conceitos e perspectivas analíticas que, entre outras coisas, problematizam os limites das análises dualistas (formal/informal, produção/reprodução, público/privado).

As autoras empenharam esforços na análise articulada das dimensões da produção e reprodução, desafiando as teses mais consolidadas no campo do trabalho e, sobretudo, alargando a compreensão sobre o trabalho. Tratou-se de não apenas compreender a condição de uma categoria de sexo (a mulher) no trabalho, mas de empreender análises em termos de relações sociais, articulando as relações de classe e de sexo. Isto é, em tal formulação de divisão e organização do trabalho, as relações de exploração e opressão são vistas de modo articulado. ${ }^{1}$

A ampliação da categoria trabalho é, portanto, uma teorização fundamental na elaboração das autoras. $O$ conceito defendido por elas abrange o não assalariado, não remunerado, não mercantil e informal. Para Hirata (HIRATA; ZARIFIAN, 2009), a noção de trabalho doméstico trouxe novas questões analíticas não compreendidas pelo debate sobre o assalariamento, como as relações afetivas e as dificuldades de sua mensuração. É a partir dessa problemática que a autora debate em termos de "produção do viver", extrapolando os limites de uma conceituação meramente economicista de produção. Essa noção compreende o trabalho para além de sua concepção moderna, incorporando o doméstico, sem, contudo, desconsiderar a centralidade do trabalho como um todo.

A conceituação de divisão sexual do trabalho tem duas acepções: uma mais descritiva da divisão sexual do trabalho diferencial entre os sexos no mercado de trabalho e como ela se 
associa à repartição desigual no âmbito doméstico - e outra, sustentada por Kergoat e Hirata, que remete à produção sistemática de desigualdades ocasionada pela divisão sexual, produzindo hierarquias não só das atividades, mas dos sexos, constituindo um sistema de gênero (HIRATA; KERGOAT, 2008, p. 263).

Assim, a definição de divisão sexual do trabalho, segundo as autoras, está ancorada em dois princípios. O princípio de separação, no qual haveria trabalhos convencionalmente femininos e masculinos, e o princípio de hierarquia, no qual os trabalhos masculinos teriam maior valor e prestígio do que os femininos.

Segundo a formulação de Kergoat (2009, p. 71), a divisão sexual do trabalho tem o status de enjeu, isto é, do que está em disputa, nas relações sociais de sexo. Compreendido como espaço de conflito de interesses entre os grupos de sexo, o trabalho e suas divisões (social, sexual, étnicoracial) constitui, para as duas autoras, uma das bases materiais centrais das relações hierárquicas entre os sexos.

Partindo dessas elaborações teórico-metodológicas, analisaremos, neste artigo, diferentes modalidades concretas da divisão sexual do trabalho em quatro setores com diferentes graus e sobreposições de formalização e informalidade, organizados sob diferentes processos de trabalho. As pesquisas que subsidiam as reflexões aqui expostas foram realizadas pelas autoras no âmbito da pós-graduação. Elas partem das referências conceituais da divisão sexual do trabalho e relações sociais de sexo e manuseiam procedimentos metodológicos qualitativos e quantitativos, como, por exemplo, o uso de entrevistas, banco de dados estatísticos (RAIS-MTE, IBGE-PNAD) e relatórios técnicos. Apesar de seguir a mesma base teórico-metodológica, essas diferentes pesquisas têm especificidades, que se reverberam na exposição de seus resultados por cada uma das pesquisadoras.

A análise da catação de materiais recicláveis expressa prioritariamente a lógica da informalidade, estejam esses trabalhadores vinculados a formas de trabalho coletivo (associações/ cooperativas) ou não. ${ }^{2}$ A modalidade de trabalho domiciliar no ramo da produção de confecções também expressa a informalidade (facções e oficinas de costura) e permanece estruturada na associação entre costureira e máquina de costura. ${ }^{3} \mathrm{O}$ trabalho em cozinhas abarca tanto o emprego formal - ainda que submetido às condições precárias comuns ao setor de comércio e serviços - quanto informal, seja no trabalho por conta própria ou na ausência de registro em

\footnotetext{
2 Pesquisa realizada entre os anos 2009 e 2014, com o apoio da Fundação de Amparo à Pesquisa do Estado de São Paulo (Fapesp) e da Coordenação de Aperfeiçoamento de Pessoal de Nível Superior (Capes). As investigações foram realizadas com catadores de materiais recicláveis autônomos e vinculados à associação de reciclagem nas cidades de Araçatuba (SP) e Marília (SP), e fez uso de técnicas de pesquisa qualitativas: etnografia, entrevista e observação participante. Para este artigo, houve uma atualização dos dados estatísticos.

3 A pesquisa desenvolve-se no âmbito do doutoramento em Ciências Sociais (Unicamp-IFCH), com financiamento da Coordenação de Aperfeiçoamento de Pessoal de Nível Superior (Capes). Na investigação, foram realizadas a observação participante e entrevistas etnográficas com costureiras e costureiros, entre os anos de 2017 e 2019, nas cidades de Caruaru, Toritama e Santa Cruz do Capibaribe, no Agreste de Pernambuco.
} 
carteira. ${ }^{4} \mathrm{~A}$ atividade industrial em manufaturas metalúrgicas, embora sob proteções relativas ao emprego formal, revela diferentes níveis de penosidade em seus segmentos e ocupações. ${ }^{5}$

Ancoradas nessas diferentes formas concretas de trabalho, pretende-se evidenciar a plasticidade e atualidade da divisão sexual do trabalho enquanto categoria teórico-metodológica desenvolvida por Kergoat e Hirata. A noção de plasticidade quer significar que há mudanças nas fronteiras da divisão sexual do trabalho, pois a divisão, ela mesma, continua existindo. Portanto a plasticidade refere-se, ao mesmo tempo, à apreensão das mudanças na reorganização do trabalho profissional (assalariado), doméstico e de cuidados, e à criação e coexistência de novos modelos de conciliação entre trabalho e família. A plasticidade assume um caráter metodológico, a partir da perspectiva comparativa entre teses e abordagens teóricas, períodos históricos, setores, lógicas produtivas etc. ${ }^{6}$

\section{A catação de materiais recicláveis e suas conexões com os trabalhos domésticos e de cuidados}

A catação de materiais recicláveis corresponde a um trabalho informal, desprotegido, precário, estigmatizado, invisibilizado e desvalorizado, mantido como base de uma cadeia de produção. O desenvolvimento da indústria da reciclagem é resultado do processo de produção, consumo e descarte massificados. Trata-se de tornar as mercadorias descartadas como lixo em matéria-prima para a produção de novas mercadorias. No Brasil, na base da cadeia produtiva dessa indústria estão as trabalhadoras e os trabalhadores catadores de materiais recicláveis, que constituem a maior parte de toda força de trabalho desse processo industrial. ${ }^{7}$

As etapas de catar, separar, compartimentar e vender os materiais se desdobram em uma série de outros processos de trabalho que variam de acordo com os tipos de materiais com que se trabalha e com o tipo de organização do trabalho. Há os trabalhadores que se vinculam a empresas, cooperativas ou associações. Há aqueles que trabalham de maneira autônoma e há ainda os trabalhadores para os quais a catação divide espaço com outros trabalhos. Todas

\footnotetext{
4 A pesquisa sobre a divisão sexual do trabalho em cozinhas profissionais baseou-se em entrevistas realizadas com homens e mulheres que trabalhavam como auxiliares, cozinheiros(as) e chefs nas cidades de São Paulo e Paris, assim como em dados do Relatório Anual de Informações Sociais (RAIS), do Ministério do Trabalho e Emprego. Foi realizada entre 2015 e 2020 com apoio da Capes.

5 A pesquisa sobre o setor metalúrgico foi desenvolvida entre 2015 e 2019 com apoio do Conselho Nacional de Desenvolvimento Científico e Tecnológico (CNPq) e da Capes. Baseou-se em dados da RAIS, em documentos técnicos setoriais e em entrevistas semiestruturadas - realizadas entre 2016 e 2018 com trabalhadores(as) e representantes sindicais ligados(as) a seis empresas dos ramos automotivo e eletroeletrônico instaladas no $\mathrm{ABC}$ e interior paulista (LAPA, 2019, p. 44-53).

6 Além disso, a plasticidade da noção de divisão sexual do trabalho envolve a repercussão do alargamento das fronteiras do conceito de trabalho, informado na consubstancialidade e coextensividade das relações sociais de classe, raça e gênero, assim como das experiências oriundas do espaço rural e dos povos tradicionais. Embora este artigo não avance nesta direção, é importante destacá-la como possibilidade.
}

7 O Movimento Nacional dos Catadores de Materiais Recicláveis (MNCR) estima que esse processo recrute cerca de 800 mil trabalhadores em todo o Brasil (MNCR, 2009). 
essas diferenças na organização e processos de trabalho de catação, contudo, são separadas e hierarquizadas entre mulheres e homens.

Propomos, portanto, analisar a catação de materiais recicláveis tendo como base a noção de divisão sexual do trabalho proposta por Danièle Kergoat e Helena Hirata, considerando o debate sobre a informalidade e uma leitura crítica sobre os dados estatísticos. Essa análise permite constatar desigualdades de gênero na catação e compreender as conexões do trabalho das mulheres catadoras com o trabalho doméstico e de cuidados, mas, além disso, a maneira como isso se coloca como oportuno para a reprodução ampliada do capital, pois como coletivo de trabalho, as trabalhadoras e os trabalhadores catadores são força de trabalho explorada pelo capital, ainda que seu processo de trabalho não esteja imediatamente subordinado a um processo de valorização, como a forma tipicamente capitalista de produção está.

Uma pesquisa realizada na cidade de Araçatuba (SP), por exemplo, demonstrou que na organização coletiva do trabalho de catação de materiais recicláveis, em uma associação de catadores, se reproduzem os princípios de separação e hierarquia, tal como Hirata e Kergoat os apresentaram. Os homens são predominantemente designados para as tarefas nas quais a força física é considerada indispensável: empurrar os carrinhos pelas ruas, prensar os materiais e carregar os caminhões com os fardos de materiais. Mas eles também são designados para as tarefas em que a força física é dispensável, mas que permanecem sendo considerados trabalhos masculinos, como dirigir o caminhão.

Enquanto as mulheres são predominantemente atribuídas às tarefas em que a separação dos materiais exige atenção redobrada e trabalho minucioso: a separação de "papel branco", a fragmentação de papéis oficiais sigilosos advindos de repartições públicas, manter atualizada a caderneta de balanço das vendas de materiais e distribuir as remunerações, além das tarefas historicamente designadas às mulheres, como organizar o cotidiano das associações, preparar as refeições dos trabalhadores e atender ao público (GRECCO, 2014).

Para além dessa descrição da separação e hierarquia de tarefas constatadas na organização coletiva do trabalho de catação, há especificidades na participação das mulheres na catação que revelam nuances mais profundas de desigualdades de gênero nesse segmento. Uma leitura crítica das estatísticas sobre esse segmento de trabalho, baseada na noção de divisão sexual do trabalho, possibilita essa análise mais aprofundada.

Do ponto de vista estatístico, as mulheres correspondem a menor parcela de trabalhadores na catação de materiais recicláveis. Elas são apenas $28 \%$ do contingente total de catadores (ANUÁRIO DA RECICLAGEM, 2019). ${ }^{8}$ Nos Empreendimentos Econômicos Solidários (EES) do segmento da reciclagem, as mulheres correspondem a 39\% dos associados (IPEA, 2013) ${ }^{9} \mathrm{e}$ representam $43,6 \%$ de todo o quadro social dos EES. No entanto estima-se que sua participação

8 Segundo dados de 2017 e 2018 da Associação Nacional dos Catadores e Catadoras de Materiais Recicláveis (ANCAT).

9 Dados Sies/Senaes, 2013. 
no trabalho de catação seja subestimada por esse tipo de dado, na medida em que parte do contingente de mulheres catadoras consideraria a catação como trabalho complementar e declararia realizar outros tipos de trabalho como atividade principal, como ser dona de casa ou empregada domésticas (IPEA, 2013).

Além disso, a remuneração pelo trabalho das mulheres catadoras seria cerca de $32 \%$ menor em relação aos homens (IPEA, 2013). ${ }^{10}$ Entre os grupos informais de EES, as mulheres são maioria, somando 63,2\% deles (IPEA, 2016) ${ }^{11}$, e quanto menor o EES, maior a participação das mulheres (ARAÚJO; DURÃES, 2010). Isto é, as mulheres estão concentradas nas maneiras ainda mais precárias e informais de organização desse trabalho, dificultando seu alcance pelas pesquisas estatísticas, especialmente se forem lidas de maneira superficial.

Esses motivos pelos quais a participação das mulheres no trabalho de catação é subestimada pelas estatísticas - considerar a catação como trabalho complementar e se concentrar em maneiras extremamente precárias e informais de organização desse trabalho - evidenciam o quão entranhada a divisão sexual do trabalho e o nexo opressão-exploração estão na organização social do trabalho e na relação dinâmica entre os trabalhos produtivos e os trabalhos domésticos e de cuidados. Para muitas mulheres, a catação é percebida como uma extensão de seu trabalho com a limpeza, além de uma maneira de complementar a renda. A responsabilização exclusiva das mulheres pelos afazeres domésticos e de cuidados, a insuficiência do Estado no provimento desses serviços e a consequente necessidade das mulheres de flexibilidade da jornada de trabalho, pode ser uma das causas dessa situação precária em que as mulheres catadoras se encontram, cujas pesquisas estatísticas, lidas de maneira rasa, não conseguem captar.

Uma pesquisa realizada na cidade de Marília (SP), por exemplo, demonstrou a complementaridade entre os trabalhos de catação e de limpeza nos cemitérios. Mulheres e seus filhos oferecem aos donos de jazigos a faxina nos túmulos de seus familiares, que são realizadas uma única vez ou periodicamente. Além da limpeza dos túmulos, essas trabalhadoras fazem o trabalho de catação de materiais recicláveis nos próprios cemitérios. Recolhem vasinhos e flores de plástico, restos de metais, restos de velas, entre outros materiais que tenham valor na reciclagem industrial da região. Esses materiais são acomodados em um canto do cemitério e são recolhidos pelas catadoras nos momentos em que percorrem a cidade com os carrinhos, catando materiais pelas ruas (GRECCO, 2014).

Esses resultados de pesquisa sobre a catação de materiais recicláveis elucidam a indissociabilidade entre os trabalhos produtivos e reprodutivos (domésticos e de cuidados), na medida em que essa dinâmica influencia a maneira como o trabalho das mulheres catadoras se diferencia do trabalho dos homens catadores. Fazem refletir sobre o quanto as conexões dos trabalhos das mulheres com os trabalhos domésticos e de cuidados, a desvalorização desses

10 A média de remuneração mensal seria em torno de um salário-mínimo, aproximadamente $\mathrm{R} \$ 975,00$ (ANUÁRIO DA RECICLAGEM, 2019). Em 2013, essa média seria em torno de R\$500,00 (IPEA, 2013).

11 Dados Sies/Senaes, 2013. 
trabalhos e, por extensão, a manutenção das mulheres em formas mais precárias e informais de trabalho, são fundamentais para a expansão do capital, tendo em vista que essas desvalorização e manutenção são fundamentais para o sucesso da geração de lucro industrial.

\section{A indústria de confecções pela lente da divisão sexual do trabalho: articulando produção e reprodução}

O trabalho domiciliar é conceitualmente impreciso ${ }^{12}$, visto que corresponde a uma enorme variedade de atividades laborais. Essas atividades abrigam diferenças significativas entre si, sobretudo acerca do processo de trabalho que repercutem no grau de autonomia das(os) trabalhadoras(es) domiciliares. É importante destacar que o incremento tecnológico reverberou no trabalho domiciliar criando novas modalidades de trabalho, como, por exemplo, o teletrabalho (home office ${ }^{13}$ ) e as plataformas online.

Apesar da imprecisão conceitual, é possível afirmar que desde a década de 1990 o trabalho domiciliar transformou-se e ampliou-se significativamente. As estratégias de redução de custos da produção por meio da externalização, subcontratação e terceirização são exemplos muito objetivos de como tanto o crescimento quanto as mudanças no trabalho domiciliar estão associadas ao novo padrão de acumulação capitalista, que produziu novas formas de gestão e organização do trabalho.

Hirata (2015) observa que as mudanças contemporâneas do trabalho no contexto neoliberal (privatização, externalização e desproteção social) operam de maneira desigual segundo o gênero/sexo. Nas palavras da autora: "As dinâmicas de classe, de raça e dos movimentos migratórios não podem ser compreendidas sem a perspectiva de gênero. $O$ gênero é um organizador-chave da globalização neoliberal" (HIRATA, 2015, p. 1).

No caso dos setores tradicionais da produção industrial têxtil, confecções e calçadista, o trabalho domiciliar é largamente utilizado mesmo antes das transformações apontadas acima. A novidade, portanto, diz respeito à compreensão de que o trabalho domiciliar é atravessado pelas tendências globais de ampliação da extração de valor por meio da intensificação do trabalho precário, informal e desprotegido executado majoritariamente pelas mulheres. Daí estabelecese o nexo opressão-exploração expresso na gestão do trabalho informal e precário que articula desigualdades de classe e sexo/gênero.

A produção têxtil e confeccionista é o segundo ramo industrial mais relevante no mercado brasileiro. Esse ramo industrial reúne 33 mil empresas, com perfil predominante de empresas de micro e pequeno porte. O setor gera emprego para 1,5 milhões de pessoas em todo o país, com maior concentração nas regiões Sudeste $(43,6 \%)$ e Sul $(30,2 \%)$. No entanto a produção da região Nordeste $(22,3 \%)$ vem crescendo nas últimas duas décadas, especialmente a

12 Para saber mais sobre as imprecisões conceituais, visitar Lavinas e Sorj (2000) e Enoque (2011).

13 Sobre o trabalho home office com foco no gênero, consultar Castro (2017). 
produção de confecções e vestuário. Uma das principais características desse ramo industrial no Brasil é a completa integração da cadeia produtiva (fiação, tecelagem, malharia, beneficiamento e confecção). Também é característica do setor a presença majoritária de mulheres na ponta da cadeia produtiva, ou seja, na produção de confecções (73\%), realizada, quase sempre, em oficinas de costura e facções (IEMI, 2016, 2017).

Apesar dos investimentos na "modernização" do setor (tecnologia, instalação e treinamento/qualificação, especialmente) a produção desse segmento industrial permanece assentada no binômio máquina de costura e costureira, marcadamente informal e precário (ABREU, 1986). O trabalho no ramo da produção têxtil, confecções e vestuário tem passado por um conjunto de transformações, dentre as quais a mais significativa consiste no fato de que as cadeias de produção se tornaram globalizadas. Como consequência dessa globalização, tem-se a divisão internacional do trabalho, que concentrou a concepção dos modelos e coleções têxteis nos países desenvolvidos, além da costura nos países e regiões onde a força de trabalho é mais barata e flexível e as atividades são realizadas em regime familiar e domiciliar (OLIVEIRA, 2013).

A cadeia regional de produção de confecções no Polo de Confecções do Agreste de Pernambuco que, embora possua características da região Nordeste, tais como o alto grau de informalidade decorrente dos padrões de acumulação nacional-regional, é atravessada por essas mudanças globais. A precariedade dessa modalidade de trabalho se expressa, inclusive, na invisibilidade das estatísticas. Os itens a seguir objetivam visibilizar o processo de trabalho e as condições de trabalho nesse setor, levando em conta a divisão sexual do trabalho, ou seja, a articulação entre produção e reprodução.

\section{Trabalho em domicílio e Divisão Sexual do Trabalho: entre jornadas, isolamento, qualificação e desproteção}

1 - Jornadas de trabalho intensivas, extensivas, intermitentes, simultâneas e o isolamento:

A divisão sexual do trabalho é crucial para a compreensão do trabalho em domicílio no ramo da produção de confecções, já que as fronteiras entre trabalho profissional e o trabalho doméstico e de cuidados são borradas, bem como as margens entre público e privado. Essa zona embaralhada produz um cotidiano de trabalho bastante complexo e precário. As jornadas de trabalho são organizadas de maneiras intensivas, extensivas, intermitentes e simultâneas, que variam entre $10 \mathrm{~h}$ e $18 \mathrm{~h}$ de trabalho. Como, por exemplo, disse uma das interlocutoras em entrevista realizada em 2017: "Não tem folga não. Não tem feriado, nem fim de semana. $O$ trabalho é muito".

A garagem, sala e/ou cozinha, cômodos da casa, agora transformados pela produção faccionada, oferecem pouca ou nenhuma qualidade para o exercício da costura. A iluminação é 
falha e as cadeiras não são ergonômicas. Outro fator bastante importante é o nível de isolamento que essa modalidade de trabalho impõe. As mulheres passam dias, às vezes semanas, sem sair de casa. E, na maioria dos casos, o isolamento é rompido apenas quando as costureiras necessitam ir até o armarinho comprar linhas e botões, e/ou quando a máquina de costura precisa de consertos.

A máquina de costura, muitas vezes localizada nas cozinhas, disputa espaço com o fogão e a mesa de jantar, transformando o cotidiano e subordinando o tempo da reprodução da vida ao tempo do trabalho na produção de confecções. A maneira como as costureiras vivenciam o espaço da casa é traduzido em expropriação e sofrimento, revelado na fala de uma interlocutora, em entrevista concedida em 2017: "A minha casa é uma bagunça e sofro com isso". As condições precárias de trabalho, e as jornadas intensivas, extensivas, intermitentes, simultâneas, bem como a instabilidade e os prazos rígidos para entrega da mercadoria e o isolamento, produzem, entre outras coisas, processos de adoecimento físico e psíquico. Esse adoecimento é visível nos relatos

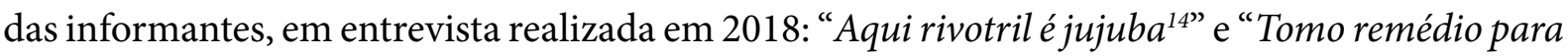
não enlouquecer". As informantes descrevem com naturalidade o uso frequente de medicação para depressão, síndrome do pânico e ansiedade como suporte para o sofrimento provocado pelo ritmo intenso de trabalho, na percepção delas.

\section{2 - Qualificação e o ofício da costura:}

Às mulheres coube o peso da obrigatoriedade com o trabalho doméstico e de cuidados, que inclui as tarefas de cuidar, ensinar, servir, atender, limpar, costurar, enfim, ocupações consideradas como "trabalho de mulher" e "lugar de mulher" e, por isso mesmo, socialmente desvalorizadas. Desse modo, a qualificação é uma expressão importante da divisão sexual do trabalho visto que, para o mundo do trabalho, os homens possuem qualificação enquanto as mulheres dispõem de qualidades (HIRATA, 2002). A atividade de costureira encaixa-se bem nessa definição, já que o aprendizado técnico, o manuseio da máquina de costura e o conhecimento do aviamento são, quase sempre, transmitidos entre as mulheres da família. Nas conversas com as informantes da pesquisa é comum ouvi-las falar do aprendizado que se inicia na infância e/ou adolescência, expressado na entrevista realizada em 2019: "Aprendi a costurar com 13 anos. Minha mãe me ensinou".

O trabalho de costurar e ajustar roupas em casa (costureiras autônomas, por exemplo) foi, ao longo do tempo, associado ao espaço doméstico e privado. E, portanto, essa presença das mulheres na produção de confecções, no contexto da externalização, tem a ver com essa qualificação sexuada instrumentalizada por esse ramo industrial. E essa diferenciação da qualificação entre homens e mulheres é produzida no âmbito das relações sociais de sexo.

14 Rivotril é o nome comercial dado a Clonazepam, uma droga usada no tratamento de síndrome do pânico e controle de ansiedade. 
3 - Desproteção social, vulnerabilidade e insegurança:

O trabalho domiciliar, para as mulheres costureiras, apresenta-se como a oportunidade de "conciliar" o trabalho profissional, o trabalho doméstico e de cuidados. Isso é verificado no relato da informante da pesquisa, produzido em 2019: “Eu costuro, olho a panela no fogo e cuido do menino".

A consequência desse modelo de conciliação ${ }^{15}$ desses trabalhos, para as costureiras, é traduzida em negação de direitos (previdência social, por exemplo), instabilidade (os contratos de trabalho são meramente verbais e os prazo para a entrega da costura é definido pelo contratante), baixo ou baixíssimos salários (equivalente a até dois salários-mínimos), longas e penosas jornadas de trabalho (entre 10h e 18h diárias), e adoecimentos (ortopédico e psíquico, sobretudo).

Para as mulheres mais jovens, somam-se também formas contemporâneas de autoassalariamento ou assalariamento disfarçado por meio da modalidade de trabalho autônomo, microempreendedor individual (MEI) e pessoa jurídica (PJ). Essas modalidades têm sido utilizadas pelos empregadores objetivando mistificar o vínculo de trabalho, ao mesmo tempo em que buscam baratear os custos da produção e força de trabalho. Aqui enquadra-se, também, o repertório empreendedor mobilizado pelo empresariado local e as jovens costureiras e designers de moda da região.

Outra importante consequência do modelo de conciliação é a delegação a outras mulheres do cuidado das crianças e limpeza da casa. É bastante comum encontrar mulheres mais velhas e/ou doentes (sofrimento mental, por exemplo) que executam o trabalho de cuidados, seja no domicílio das costureiras, seja na casa da vizinha transformada em uma pequena creche improvisada. A negociação entre trabalho doméstico e de cuidados e o trabalho profissional atualiza e retroalimenta os modelos de conciliação ao mesmo tempo em que confunde formas de exploração e amparo/ajuda. Refere-se aqui à ajuda, pois entre essas mulheres não há o grau de hierarquia retratado na literatura que analisa a relação entre as mulheres executivas e com postos de responsabilidade e empregadas domésticas, por exemplo.

\section{A segregação por sexo em cozinhas profissionais}

As cozinhas são um espaço interessante de observar como a divisão sexual organiza o trabalho, hierarquiza as atividades e coloca homens e mulheres em relação de permanente tensão (relações sociais de sexo), definindo performances e comportamentos profissionais.

Os princípios da separação e hierarquia se fazem presentes com muita clareza e organizam o trabalho que ocorre nesse espaço. Para além da separação entre a cozinha doméstica e a cozinha profissional, em que a primeira faz parte do trabalho doméstico e, portanto, é associada

15 Para a análise das mudanças dos modelos de conciliação, ver Hirata (2015). 
ao trabalho feminino, desvalorizado e invisibilizado, e a segunda constitui o trabalho visível, de prestígio e masculino, tal divisão também se expressa dentro da cozinha profissional.

No caso da cozinha doméstica, em anos recentes - na medida em que transformações sociais têm se operado paulatinamente, principalmente em função do movimento feminista que tem procurado dar visibilidade ao trabalho doméstico enquanto trabalho, mesmo quando não remunerado - há uma pressão crescente para que os homens assumam a parte que lhes cabe nesse conjunto de atividades. Bruschini e Ricoldi (2012) observaram que a contribuição masculina para o trabalho doméstico aparece na forma de "ajuda", o que denota, por um lado, que esse trabalho continua sendo atribuição principal das mulheres e, por outro, que os homens realizam as tarefas que sobram, ou as que escolhem fazer. À medida que a cozinha vai se tornando gastronomia, e cada vez mais associada a uma arte, a um talento, a um trabalho positivo, mesmo a cozinha doméstica vai se masculinizando.

$\mathrm{Na}$ cozinha profissional, de restaurantes e outros estabelecimentos de comida preparada, há uma separação de trabalhos de homens e de mulheres, em que as mulheres estão associadas à cozinha fria e à confeitaria, e os homens associados à cozinha quente, à grelha, à chapa, aos fornos, à carne, assim como ao trabalho de chef. Há uma hierarquia clara entre três ocupações: auxiliar ou assistente, que é a ocupação mais baixa ou com menos experiência, um cargo de entrada, que geralmente trabalha junto a um(a) cozinheiro(a) e faz o trabalho de mis-enplace $^{16}$, limpeza e higienização; o(a) cozinheiro(a) que faz o trabalho de preparo, cozimento e montagem; e o(a) chef, a pessoa com mais autoridade na cozinha, que precisa ser cozinheiro(a), mas é, sobretudo, um(a) administrador(a).

O princípio da hierarquia se expressa na concentração das mulheres nas funções de auxiliar de cozinha e cozinheira, enquanto os homens majoritariamente ocupam o cargo de chef $^{17}$, apesar de as mulheres serem a maioria dos empregados no setor ${ }^{18}$. O trabalho do(a) chef é gerir os funcionários da cozinha, administrar os insumos, controlar tudo que entra e sai dos estoques, a relação com os clientes, responsabilidade sobre o cardápio e, em última instância, sobre a identidade do estabelecimento, sobre o tipo de comida que vai ser servida.

A hierarquia do trabalho baseia-se na autoridade do(a) chef. Principalmente na hora do serviço, uma pressão forte se exerce sobre os funcionários e todos precisam cumprir seu papel. Por remeter a uma hierarquia militar, a posição de chef tem características masculinas, como a voz de comando, a liderança e certo grau de agressividade — pois cabe ao(à) chef manter o ritmo do trabalho da cozinha como um todo, portanto é ele(a) que exerce a pressão. O princípio

16 Mis-en-place: do francês, literalmente, colocar no lugar. É o trabalho de pré-preparo dos alimentos, que consiste em tarefas como lavar, higienizar, descascar, cortar, porcionar, entre outras, antes de cozinhar, de fato.

17 De acordo com dados da RAIS (2017), no Brasil, do total de empregados formalmente como chefs, 59,7\% são do sexo masculino.

18 Ainda segundo a RAIS (2017), eram 476.104 trabalhadores formalmente empregados no Brasil em restaurantes e outros estabelecimentos de alimentação e bebidas, serviços de catering, bufê e outros de serviços de comida preparada, sendo $67,2 \%$ mulheres. 
da hierarquia se expressa numa atribuição de características para o trabalho de liderança que são condicionadas por elementos do gênero masculino. Cabe às mulheres que chegam a esses postos de liderança criar estratégias para poder exercer autoridade.

Há uma separação entre "trabalhos de homens" e "trabalhos de mulheres", em que os trabalhos de homens têm mais valor e prestígio do que o das mulheres. Muito associado à força física e à vitalidade, o preparo de carnes e o manuseio de grandes partes dos animais, que remete a um passado cavernícola de domínio da natureza, é um trabalho desempenhado, sobretudo, pelos homens (BRIGUGLIO, 2020).

As mulheres são mais direcionadas para a cozinha fria, em ocupações como garde manger (legumes, saladas, frutas), a praça de entradas (pratos menores e mais simples) e a confeitaria (bolos, doces e sobremesas). O trabalho feminino na cozinha é associado a menos demanda de força física (o que na prática não é exatamente verdade, uma vez que os legumes e frutas precisam ser transportados e carregados em sacos ou caixas pesados), mas muita delicadeza, precisão e atenção aos detalhes. A diferenciação entre homens e mulheres no mundo profissional pode ser explicada por uma série de razões, entre as quais Hirata (2015, p. 8) destaca o tipo de emprego (setor de atividade, contrato de trabalho) e "a construção social das mulheres como sendo tecnicamente incompetentes".

Os papéis de gênero e a associação de características "naturalmente" femininas fazem com que as mulheres se sintam frequentemente obrigadas a provarem que têm tanto mérito e capacidade quanto os colegas homens, que elas também merecem estar lá. Cabe às mulheres se adaptarem ao ambiente de trabalho e, caso não consigam, elas são consideradas o problema.

Todavia essa categorização de "feminilidade" associada ao trabalho delicado e monótono está associada às necessidades produtivas, já que toda essa delicadeza atribuída às mulheres, que as tornaria incapazes de trabalhos pesados e insalubres, desaparece e elas passam a ser consideradas aptas para esses nos momentos em que os setores produtivos demandam. SouzaLobo (2011) questiona os critérios de presença/ausência de força na organização da divisão sexual do trabalho ao reivindicar as comparações intersetoriais, mostrando que, no Brasil, quando se necessita das mulheres como cortadoras de cana, por exemplo, os critérios de delicadeza e trabalho leve desaparecem.

Carregar peso e transportar caixas são atividades que podem comprometer a saúde tanto dos homens quanto das mulheres, e oferecem risco à saúde de ambos. Ainda que novas tecnologias possam aliviar esse tipo de trabalho (como carrinhos, roldanas e elevadores), o uso da força física é visto como uma característica muito positiva, como um rito de passagem pelo qual quem deseja trabalhar na cozinha precisa passar. Nesse sentido, muitas mulheres preferem se esforçar para carregar peso em vez de pedir ajuda, por compreenderem que isso pode ser interpretado como uma fraqueza, como algo que poderá ser usado contra elas. 
Como observaram Kurnaz, Selçuk Kurtulus e Kiliç (2018, p. 128), é necessário que as mulheres chefs trabalhem mais e mais duro que os homens, assim como é importante que elas "amem" o trabalho para criarem mais espaço para elas mesmas nesse setor dominado por homens. "Embora elas sejam bem-sucedidas em existir em um campo dominado pelo masculino, elas sentem a obrigação de serem aceitas pelos homens".

Há uma trama de poder por trás da naturalização das atividades femininas e masculinas, sendo as masculinas mais valorizadas. Em um ambiente como as cozinhas profissionais, onde há muita pressão, onde o poder se exerce sobre os(as) subalternos(as) na forma de gritos, de ameaças e de outras agressividades, onde as jornadas e o cotidiano do trabalho são extenuantes e muito exigentes, constrói-se a ideia de que apenas resistem a esse trabalho os que são mais fortes. Às mulheres que pretendem sobreviver nesse espaço só lhes resta se tornarem mais fortes, em alguma medida, se masculinizarem, sob pena de sofrerem assédio ou serem demitidas.

A tensão que permeia as relações entre homens e mulheres nesse ambiente e nas relações de trabalho nesse setor não se limita a características pessoais ou conflitos entre indivíduos, mas como alertaram Kergoat e Hirata, são relações de tensão social entre os grupos de mulheres e homens. A ideia de que as relações sociais de sexo se estruturam em torno de um enjeu, em função de algo que está em disputa, fica evidente nas relações de trabalho nas cozinhas, onde os princípios da divisão sexual do trabalho se expressam de forma clara.

\section{Leveza, peso, técnica e penosidade em questão: a divisão sexual do trabalho industrial}

A composição da força de trabalho industrial metalúrgica no Brasil é hegemonicamente masculina. Embora o trabalho em tais indústrias seja caracterizado pela formalidade de contrato, não há uniformidade das condições de emprego em seus segmentos e esses possuem diferentes configurações de divisão sexual do trabalho. O segmento automotivo, de baixa presença feminina, tem salários mais altos e empregos mais protegidos, enquanto o eletroeletrônico ${ }^{19}$ tem participação feminina mais significativa e remuneração média inferior. Esses são os dois segmentos nos quais se alcançou maior participação feminina dentro do setor metalúrgico ${ }^{20}$.

19 Trata-se de indústrias, sobretudo transnacionais estrangeiras, instaladas no Brasil, país para o qual se deslocam operações específicas de suas cadeias globais de produção, o que remete a um debate sobre a conjugação entre divisão internacional e sexual do trabalho na conformação atual desses segmentos, conforme desenvolvido em Lapa (2019, p. 56-62).

20 A participação máxima de mulheres no setor metalúrgico brasileiro já alcançada foi de 19,14\%, e está em queda desde então (DIEESE, 2017). No segmento automotivo, elas são quase um quinto (19,8\%) da força de trabalho, e no eletroeletrônico, elas são cerca de um terço (34,47\%). É nesses mesmos segmentos que se verifica a inferioridade salarial feminina mais alta entre todas da indústria metalúrgica: no automotivo é de 28,28\%, enquanto no eletroeletrônico, é de 36,3\%, demonstrando uma tendência à maior desigualdade salarial nos segmentos mais feminizados (LAPA, 2019, p. 127). 
Tais atuais fronteiras da participação do trabalho fabril feminino repõem o "princípio da separação" ${ }^{21}$, por meio do qual atribui-se a homens ou mulheres trabalhos socialmente entendidos como femininos ou masculinos, e a partir de onde constroem-se, também, valorações distintas dos trabalhos segundo o sexo de quem os efetua.

Discutir os estereótipos sobre as capacidades e limitações femininas é uma das formas de abordar a construção da segregação e a hierarquia dos sexos no trabalho. Apesar de serem frequentemente desacreditadas em fábricas pouco feminizadas, como as montadoras automotivas, mulheres alcançam postos considerados masculinos e neles demonstram plena capacidade técnica e física de desempenharem seus trabalhos - situação que ajuda a questionar a dita e naturalizada "incapacidade feminina". De outra parte, no segmento eletroeletrônico, cuja fabricação de equipamentos de informática e de celulares utiliza trabalho eminentemente feminino, existe uma pressuposta compatibilidade entre trabalhos que requerem delicadeza e minúcia e as mulheres.

Duas das justificativas para o lugar ocupado pelas mulheres na produção de bens, segundo as operárias e operários que trabalham nas indústrias automobilística e eletroeletrônica paulistas, bem como de seus representantes sindicais, remetem às questões das habilidades e qualificações necessária para o trabalho, que giram em torno do binômio força versus delicadeza e da relação com os instrumentos de trabalho, reiterando a tendência ao afastamento de mulheres da operação de máquinas.

Autoras como Kergoat (2018) e Souza-Lobo (2011) desenvolveram estudos questionando justificativas criadas para a alocação (e segregação) de mulheres em determinados postos das fábricas. Como discute Kergoat, associar o trabalho das operárias à uma ideia de feminilidade que rima com fragilidade e delicadeza ocasiona dificuldade de reconhecimento (e a compensação) do caráter penoso das suas condições de trabalho nos postos repetitivos que comumente ocupam. Segundo a autora, "a força física é remunerada, mas não a destreza manual, a minúcia ou a resistência nervosa", isso sob argumento de que "tais qualidades não seriam adquiridas através de uma formação, mas inerentes ao sexo feminino" (KERGOAT, 2018 ${ }^{22}$, p. 33). Assim, reproduzse uma visão restrita de que trabalho pesado ou penoso - e que merece compensações - é apenas o que requer força (real ou no plano das representações).

Há, no segmento eletroeletrônico, uma predominância absoluta das mulheres nas atividades de montagem manual dos menores equipamentos, cujos principais requisitos são a delicadeza, minúcia e agilidade. Tais atividades carregam consigo, ainda hoje, a representação de "leves". A penosidade ocultada de seu trabalho não reside unicamente no fato de que se

21 Que se expressa na proporção de homens e mulheres nas principais regiões de concentração dos segmentos automotivo e eletroeletrônico: há apenas $8 \%$ de mulheres no segmento automotivo do ABC Paulista, enquanto elas são $56 \%$ da força de trabalho no eletroeletrônico do interior paulista, conforme dados levantados junto à RAIS em 2019 (LAPA, 2019, p. 108-109).

22 Texto publicado pela primeira vez em 1978, em francês. 
realizam operações minuciosas, repetitivas, em ciclos curtos, em ritmo acelerado, constante e imposto (uma fábrica investigada produzia um notebook por minuto, 3 mil por hora e 24 mil por dia). Diz respeito, também, ao fato de que há postos que requerem, sim, o uso de força para o carregamento de pesos (de caixas, de equipamentos, de carrinhos com peças, o dia todo) - conforme relatado por operárias. Sendo em razão da repetitividade ou em razão do real carregamento de pesos, há nesses trabalhos o requisito de esforço físico que o distancia da alcunha de "leve".

Outra justificativa para a divisão sexual nas fábricas que se evidencia falaciosa é a pressuposta inabilidade feminina para trabalhos considerados demasiadamente "técnicos" ou que demandam operar máquinas. $\mathrm{O}$ fato de as mulheres serem as primeiras a ocupar certos postos de fábricas automotivas do ABC em plenos anos 2000 e 2010 - como eletricista de manutenção, operadora de empilhadeira ou soldadora no setor de armação - quebra, na prática, embora de forma tardia, o argumento da incapacidade. A frase repetida por trabalhadoras entrevistadas: "não é força, é jeito", "não é força, é habilidade", entre outras variações, mostra que há alternativas para que mulheres menos fortes trabalhem nas fábricas. Ao mesmo tempo, a presença de homens menos fortes em postos como o de estamparia, reconhecido como um posto penoso, revela que o que acaba sendo colocado em operação não é o critério da presença ou ausência de força ou de habilidade técnica, mas o critério do gênero de quem trabalha.

A problemática da necessidade de força para a realização das operações nas fábricas não pode ser ignorada, tampouco absolutizada. Há recursos técnicos que podem diminuir a necessidade de força em diversos postos, como a automatização de certos postos "duros", a exemplo do que se conquistou em uma das fábricas com a mecanização de uma operação de transporte de pneus que antes precisavam ser carregados "no braço". Há também técnicas ensinadas por colegas a operárias de montadoras de veículos para, por exemplo, carregar grandes peças, como portas de caminhões ("eu já tinha o jeito(...)você já pegava ela, colocava no trilho e ia empurrando. (...) enquanto você não tem essa experiência, vai se esforçar mais"). Há inclusive trabalhadoras que desenvolvem seus próprios macetes, para evitar pedir ajuda para homens e serem consideradas inaptas para seu trabalho, como a adaptação de instrumentos com alavancas que permitem maior aplicação de força, pois, segundo uma delas, "nem sempre você precisa executar com a força do corpo". Tais exemplos favorecem o argumento de que cada vez menos a força física pode ser considerada um impedimento para que mulheres realizem funções nas fábricas automotivas.

Há de se discutir, também, critérios para alocação dos homens na divisão sexual dos postos. No segmento eletroeletrônico, conforme relata Liliane $e^{23}$, havia um tipo de "negociação" de operários da linha com os líderes, que criavam vínculos entre si fora do ambiente de trabalho (por exemplo, jogavam futebol juntos), o que resultava em livrá-los dos postos mais duros, nos quais as operárias acabavam predominando em algumas linhas: "a maioria dos homens faziam 
as coisas mais leves. (...) tinha umas partes que a gente via homens que pegavam peso mesmo, mas tinha parte que a gente via uns rapazes fortes, altos, pegando etiqueta, enquanto só mulher pegava peso. Então, ia falar alguma coisa, aquele cara lá era amigo do líder". Essa problemática remete ao identificado em outras pesquisas, sobre haver alocação de mulheres nos postos mais duros da fábrica, rejeitados por outros operários homens.

No segmento automotivo, conforme relata Catarina ${ }^{24}$, há trabalhos que homens em geral "não conseguem fazer", como o de dar pontos de solda menores e mais numerosos no setor de armação de veículos: "Não sei se é porque eles não querem trabalhar lá, mas eles dão ponto em lugar errado, aí solta. Eles não ficam olhando se o ponto está solto".

A esse respeito, Souza-Lobo (2011) constatara, em suas pesquisas sobre operárias do ABC nos anos 1980, que os homens "não são muito hábeis para determinadas tarefas", explicando que "eles não querem aprender justamente porque se trata de tarefas penosas" (SOUZA-LOBO, 2011, p. 86-87). A autora analisa que "os homens podem recusar alguns constrangimentos. Homens e mulheres podem resistir quando querem. A resistência masculina é descrita como uma afirmação de poder, a das mulheres como negligência, irresponsabilidade, falta de interesse" (SOUZA-LOBO, 2011, p. 87).

Assim, é relevante compreender que a presença concentrada de mulheres em determinadas funções da indústria metalúrgica (como a montagem manual) não decorre somente dos atributos "femininos" - como minúcia, destreza etc. -, mas é também consequência do impedimento de seu acesso a outros postos menos penosos e mais bem remunerados. Deste modo, é preciso compreender a posição das mulheres no processo produtivo não somente como "gueto feminino", mas também como "residual" do trabalho que homens não querem fazer25.

A divisão sexual do trabalho na indústria se mostra, assim, como um ponto de observação relevante de justificativas questionáveis sobre o estereótipo do feminino e do masculino de trabalhadores(as), assim como provoca a questão de que se trata de relações sociais de sexo/ gênero desiguais, nas quais homens, quando podem, escapam de trabalhos repetitivos e penosos, que acabam relegados para mulheres. Essa situação se revela tanto em atividades masculinizadas e mais bem remuneradas, como a da montagem automotiva, como em atividades feminizadas e mais mal remuneradas, como a montagem eletroeletrônica. À qualificação não reconhecida das operárias e à penosidade ocultada de sua atividade, que redundam em sub-remuneração feminina, soma-se o impedimento de que operárias acessem postos mais bem remunerados e menos penosos. Tais constatações trazem elementos para a compreensão das particularidades da exploração do trabalho feminino, submetido aos ditames do capital conjugados aos da divisão

24 "Catarina" (nome fictício) 51 anos, operária na armação de veículos. Entrevistada em 2018.

25 Como analisou Tabet (2005), mesmo em profissões que se constroem como tradicionalmente femininas, não existem atividades exclusivamente femininas, havendo uma tendência de os homens assumirem as funções ligadas à operação de máquinas maiores/instrumentos mais complexos, excluindo as mulheres desses postos e relegandoas às atividades a serem cumpridas sem instrumentos (manualmente) ou com instrumentos simples (TABET, 2005, p. 68). 
sexual.

\section{Breves considerações}

Os resultados de pesquisa aqui apresentados se entrecruzam com a finalidade de demonstrar a atualidade do conceito de divisão sexual do trabalho para os estudos do trabalho contemporâneos e como a conceituação feita por Hirata e Kergoat o torna uma chave de leitura metodológica.

Nas quatro "modalidades concretas" discutidas aqui, os princípios de separação e de hierarquia do trabalho entre os sexos revelam uma série de desigualdades, como a invisibilidade, adoecimentos, isolamento, jornadas de trabalho intensivas, extensivas, intermitentes, simultâneas, o não acesso aos direitos sociais associados ao trabalho, o não reconhecimento da qualificação feminina, as distorções na atribuição/retribuição de trabalhos penosos, a desigualdade de remuneração, a extensão dos trabalhos domésticos e de cuidados - historicamente atribuídos às mulheres.

As desigualdades entre mulheres e homens na organização social do trabalho contemporâneo são constatadas de maneira mais imediata no trabalho industrial, tipicamente capitalista, em que, desde sua concepção, utiliza o trabalho de mulheres e crianças como uma maneira de aprofundar a exploração e demonstra a reprodução de justificativas questionáveis sobre o estereótipo do feminino e do masculino de trabalhadores(as), como nas indústrias automobilística e eletroeletrônica. Já o trabalho nas cozinhas, que historicamente se estruturou como trabalho designado às mulheres em sua dimensão doméstica tradicional, em âmbito mercantil explicita a tensão que permeia as relações sociais de sexo.

No mesmo sentido, a modalidade do trabalho na confecção, concebida como trabalho industrial tipicamente capitalista e feminino, em sua dimensão contemporânea é atravessado por diversas mudanças globais e se estrutura em intensa informalidade, sendo permeado por tensões relativas ao trabalho em domicílio, que incidem de maneiras diferentes entre as trabalhadoras e os trabalhadores. Por fim, a catação de materiais recicláveis recoloca a maneira típica de organização do trabalho fabril ao mesmo tempo em que se organiza de maneira conectada à dinâmica reprodutiva do trabalho das mulheres, tanto como uma extensão quanto como justificativa para a informalidade e a precariedade.

Essas análises permitem, também, estender a compreensão da divisão sexual do trabalho para além do entendimento moderno de trabalho, da centralidade do trabalho assalariado, da lógica econômica, ao percorrer as nuances entre maneiras formais e informais de organização do trabalho e direcionar a análise para o conjunto de relações sociais que atravessam o campo social. Apesar dessa extensão da noção de trabalho, o compreendemos como central no enfrentamento às desigualdades sociais, assentado em uma agenda feminista democrática, que pressupõe a construção de ações e formas de resistência coletivas. 


\section{Referências}

ABREU, Alice. O avesso da moda: trabalho a domicílio na indústria de confecção. São Paulo: Hucitec, 1986.

ARAÚJO, Angela Maria Carneiro; DURÃES, Bruno. Informalidade e desproteção social: uma realidade para a maioria das mulheres trabalhadoras. In: COSTA, Albertina et al. (org.). Divisão sexual do trabalho, Estado e crise do capitalismo. Recife: SOS Corpo, 2010. p. 83-114.

ANUÁRIO DA RECICLAGEM 2017-2018. ancat.org.br. São Paulo: ANCAT, 2019. Disponível em: https://ancat. org.br/wp-content/uploads/2019/09/Anua\%CC\%81rio-da-Reciclagem.pdf Acesso em: 27 jan. 2021.

BRASIL. Relação Anual de Informações Sociais-RAIS. Brasília, Ministério da Economia. Disponível em: https:// bi.mte.gov.br/bgcaged/ Acesso em: 27 jan. 2019.

BRIGUGLIO, Bianca. Cozinha é lugar de mulher? A divisão sexual do trabalho em cozinhas profissionais. 2020. Tese (Doutorado em Ciências Sociais) - Instituto de Filosofia e Ciências Humanas, Universidade Estadual de Campinas, Campinas, 2020.

BRUSCHINI, Maria Cristina e RICOLDI, Arlene. Revendo estereótipos. O papel dos homens no trabalho doméstico. Revista de Estudos Feministas, Florianópolis, v. 20, n. 1, p. 259-287, jan./abr. 2012.

CASTRO, Bárbara. As armadilhas da flexibilidade: trabalho e gênero no setor de tecnologia da informação. São Paulo: Annablume, 2017.

DIEESE. A inserção das mulheres no ramo metalúrgico: uma década de avanços, desigualdades e lutas. São Bernardo do Campo: DIEESE CNM/CUT FEM-CUT/SP, 2017.

ENOQUE, Alessandro G. Por Trás dos Fios Invisíveis: Configurações do Trabalho Domiciliar no Brasil Contemporâneo. In: CONGRESSO BRASILEIRO DE SOCIOLOGIA, 15., 2011, Curitiba. Anais do XV Congresso Brasileiro de Sociologia. Curitiba: UFPR, 2011. p.1-27.

GRECCO, Fabiana Sanches. Produção e Reprodução capitalista na indústria da reciclagem. 2014. Dissertação (Mestrado em Ciência Sociais) - Faculdade de Filosofia e Ciências de Marília, Universidade Estadual Paulista "Júlio de Mesquita Filho", Marília, 2014.

HIRATA, Helena. Mudanças e permanências nas desigualdades de gênero: divisão sexual do trabalho numa perspectiva comparada. Fundação Friedrich Ebert Stiftung Brasil, São Paulo, n.7, p. 1-22, out. 2015.

HIRATA, Helena. Nova Divisão Sexual do Trabalho? Um olhar voltado para a empresa e a sociedade. São Paulo: Boitempo, 2002.

HIRATA, Helena; KERGOAT, Danièle. Divisão sexual do trabalho profissional e doméstico: Brasil, França, Japão. In: COSTA, Albertina O. et al. (org.). Mercado de Trabalho e Gênero: Comparações Internacionais. Rio de Janeiro: Editora FGV, 2008. p. 263-278.

HIRATA, Helena; ZARIFIAN, Philippe. Trabalho (conceito de). In: HIRATA, Helena et al. (org.). Dicionário crítico do feminismo. São Paulo: Editora UNESP, 2009. p. 251-256.

IEMI. Estudo da competitividade dos setores têxtil e confeccionista no estado de Pernambuco. Recife: Governo do Estado de Pernambuco/Secretaria Estadual de Desenvolvimento Econômico; Núcleo Gestor da Cadeia Têxtil e de Confecções em Pernambuco, 2017.

IEMI. Relatório setorial da indústria têxtil brasileira. São Paulo: IEMI, 2016.

IPEA. Os novos dados do mapeamento de economia solidária no Brasil: nota metodológica e análise das dimensões socioestruturais dos empreendimentos. Brasília: Instituto de Pesquisa Econômica Aplicada, 2016.

IPEA. Situação social das catadoras e dos catadores de material reciclável - Brasil. Brasília: Instituto de Pesquisa Econômica Aplicada, 2013. 
KERGOAT, Danièle. Divisão sexual do trabalho e relações sociais de sexo. In: HIRATA, Helena et al (org.). Dicionário Crítico do Feminismo. São Paulo: Editora UNESP, 2009. p. 67-75.

KERGOAT, Danièle. Operários=operárias? Proposições para uma articulação teórica de duas variáveis: sexo e classe social. In: KERGOAT, Danièle. Lutar, dizem elas... Recife: SOS Corpo, 2018. p. 23-58.

KURNAZ, Alper; SELÇUK KURTULUS, Sila; KILIÇ, Burhan. Evaluation of Women Chefs in Professional Kitchens. Journal of Tourism and Gastronomy Studies, v. 6, n. 3, p. 119-132, out. 2018.

LAPA, Thaís S. O gênero do trabalho operário: condições de trabalho, divisão sexual e práticas sociais em indústrias metalúrgicas dos segmentos automotivo e eletroeletrônico. 2019. Tese (Doutorado em Ciências Sociais) - Instituto de Filosofia e Ciências Humanas, Universidade Estadual de Campinas Universidade Estadual de Campinas, Campinas, 2019.

LAVINAS, Lena; SORJ, Bila. O trabalho a domicílio em questão: perspectivas brasileiras. In: ROCHA, Maria Isabel Baltar (org.). Trabalho e gênero: mudanças, permanências e desafios. São Paulo: Ed. 34, 2000. p. 211-236.

MNCR. Formação nível 1: caminhar é resistir. São Paulo, Movimento Nacional dos Catadores de Materiais Recicláveis, 2009.

OLIVEIRA, Roberto Verás de. O Polo de Confecções do Agreste de Pernambuco: elementos para uma visão panorâmica. In: OLIVEIRA, Roberto Verás de; SANTANA, Marco Aurélio (org.) Trabalho em Territórios produtivos reconfigurados no Brasil. João Pessoa/PB: Editora da UFPB, 2013. p. 233-278.

SOUZA-LOBO, Elisabeth. A classe operária tem dois sexos. Trabalho, dominação e resistência. São Paulo: Ed. Perseu Abramo, 2011.

TABET, Paola. Las manos, los instrumentos, las armas. In: CURIEL, Ochy; FALQUET, Jules (org.). El patriarcado al desnudo. Tres feministas materialistas: Colette Guillaumin - Paola Tabet - Nicole Claude Mathieu. Buenos Aires: Brecha Lesbica, 2005. p. 57-129.

Recebido em 09/03/2020

Aceito em 17/12/2020 